\title{
NOMBRES, EXILIOS, ENCIERROS. SUSANA GERTOPÁNY LA(S) ESCRITURA(S) JUDÍA(S) DE PARAGUAY
}

\author{
Liliana Ruth Feierstein*
}

\section{Resumen}

La comunidad judía de Paraguay es pequeña y casi desconocida en el ámbito de los estudios judaicos. A través de un breve análisis de las obras de una de sus voces literarias más interesantes, Susana Gertopán, el artículo intenta agudizar el oído para identificar algunos tópicos recurrentes y dolorosos de esa historia: las marcas del exilio, el problema del nombre, la transmisión intergeneracional del trauma de la Shoá, las dificultades de adaptación de los inmigrantes del este europeo a este territorio extraño y tropical y, en resumidas cuentas, las huellas de la vivencia judía en un país eclipsado durante décadas por una dictadura que lo convirtió en un gueto aislado del mundo. Donde, sin embargo, creció la vida. Plena de cicatrices.

Palavras clave: Gertopán, romance, exilio, Paraguay

\section{Abstract}

The Jewish community in Paraguay is small and almost unknown in the field of Jewish studies. Through a short analysis of the works of one of this community's most interesting literary voices, Susana Gertopán, the article attempts to pay close attention, so as to identify several recurring and painful topics from this chapter of history: the distinguishing features of exile, the challenges of the name, intergenerational transmission of the trauma of the Shoah, the problems of the immigrants from Eastern Europe in adapting to this strange and tropical

\footnotetext{
* Doctora en Filosofía por la universidad Heinrich Heine de Düsseldorf. Actualmente es investigadora en la Universidad de Constanza. Autora de los libros Habitar la Letra: Judaísmo, escritura y transmisión y Von Schwelle zu Schwelle (la versión en espanol De umbral a umbral. Pensadores judeo-alemanes y la modernidad está actualmente en prensa).<lili.feierstein @ googlemail.com>
} 
land, and, in short, the traces of Jewish life in a country that was in eclipse for decades because of a dictatorship that turned it into a ghetto, isolated from the world. But where, nevertheless, life continued to grow. Full of scars.

Keywords: Gertopán, novel, exile, Paraguay

a condición de identidad de un pueblo - forjada durante siglos y trasladada
al continente americano por inmigrantes que llegan desde fines del siglo XIX - va decolorándose con el paso de las generaciones. Pierde volumen, deja lugar a tonos y confidencias más ligadas a la influencia de la tierra americana, a su clima, a su lengua, y a su realidad cotidiana, social y política.

Una manera significativa de encarar esta historia - individual y comunitaria puede encontrarse en la producción novelística de Susana Gertopán (Asunción del Paraguay, 1956), donde aparece un alto contenido metafórico-ficcional respecto a la memoria del pasado lejano, del reciente y de la más pura actualidad. Gertopán proviene de un país, el Paraguay, cuya colectividad judía ha sido poco estudiada y que, sin embargo, funcionó, en los años de la Shoá y los inmediatamente posteriores, como lugar de residencia - o de paso - para muchos judíos impedidos de ingresar al continente por razones legales o políticas.

Los antecedentes históricos judíos en el Paraguay durante la época colonial son muy escasos: se afirma que ciertas familias paraguayas, como los Gaona o los Pérez y Pereira, son de origen criptojudío, exilados de España durante el período de la expulsión. A inicios de la segunda mitad del siglo XIX llegan inmgrantes judíos en pequeño número desde Europa, pero es en la primera década del siglo XX cuando se establecieron algunas familias provenientes de Rusia que comienza a organizarse la colectividad de ese origen. Hacia 1917 los judíos ya eran unos 600 y en su mayoría procedían de Polonia, Rusia, Turquía, Alemania y Francia.

Hacia 1970 se calculaba la presencia de un millar de judíos, en una población total de 2.100.000 habitantes. Es decir, un porcentaje aproximado al 0,50\% de la población. Prácticamente la totalidad de ellos se concentraban en Asunción, la capital de la república, que en esa misma fecha tenía 350.000 habitantes. Es probable que el escaso número de integrantes de la colectividad explicara su concentración en un barrio específico, que es el punto de partida de la primera novela de Susana Gertopán. 
Los judíos tuvieron escasa participación en la vida política nacional, pero sus sucesivas generaciones se destacaron en actividades culturales y universitarias, así como en el campo de la creación artística. El país no tiene una trayectoria de actividades antisemitas organizadas, aunque a finales de la Segunda Guerra Mundial se hablaba de grupos de criminales de guerra nazis que huyeron de Europa y se establecieron en zonas aisladas del país.

En la primera de las novelas que integran la trilogía Barrio Palestina (1998), la referencia a ese especie de gueto donde se concentraron los primeros inmigrantes judíos, en los años 30' del siglo pasado, tiene una amplia base de partida (todo el primer tercio del libro) donde se describe la vida judía en lugares como Varsovia o Vilna, cuyas heladas estepas fueron abandonadas por los inmigrantes para arribar a una tierra tropical y desconocida, con toda su carga de dramatismo y nostalgia. El narrador, Moíshele, crecerá junto con la novela, una interesante estrategia de la autora que, así, puede, representar los conflictos familiares y personales suavizados por la mirada del niño que las relata desde afuera: el arco va desde las primeras rebeldías en la antisemita capital polaca hasta sus enojos mientras se despliega la difícil aclimatación de sus padres, Dóvid y Reitze, en las desconocidas tierras guaraníes.

Sin embargo es Feíguele, el hermanito menor de Moíshele, el personaje más interesante. Frágil como el pajarito al que su nombre alude, asmático, se expresa a través de su silencio. Inmigrante, la imposibilidad de la adaptación. Tal como en la canción de cuna de Itzik Manger, en donde el niño quiere ser un pájaro (Feíguele) y la madre le pone tantos vestidos para protegerlo que finalmente le impide "volar" su vida, en la novela la madre de este niño frágil lo ahoga en el verano paraguayo "cuidándolo" como si aún estuvieran en Polonia. Feíguele crecerá como una sombra triste del judaísmo europeo mal exilado en tierras americanas. Moíshele en cambio canalizará su rebeldía inmigrando hacia el final de la trama al recién fundado Estado de Israel.

En El nombre prestado (2000), la segunda novela de esa serie, algunos de esos inmigrantes - años después - siguen viviendo en un gueto imaginario, bajo premisas ciegamente aceptadas y repetidas como leit-motiv de un destino inexorable ("No todo lo deseable es posible" o "Suponer que los acontecimientos se desarrollarían de acuerdo a como uno los imaginaba siempre me pareció muy infantil, aunque más de una vez, siendo ya adulto, igualmente caía en la 
red de los deseos irrealizables"). Pero, en este caso, la siguiente generación reacciona de manera violenta y opuesta, para diferenciarse. Esta vez, los personajes centrales son la pareja irreconciliable de padre e hijo, enfrentados y sin posibilidad de entendimiento entre ellos. El progenitor es un antiguo prisionero de Auschwitz que pretende trasladar en Paraguay - su propia sobrevivencia a la del judaísmo europeo del que es testimonio viviente. Su hijo José - Iósele, luego Alejandro en la nueva identidad que adopta - es un hombre de 50 años cuando comienza la acción. Nacido en América Latina, judío secular con experiencia de algunos años en Israel, se niega a aceptar esa herencia cuya memoria le es ajena pero, a la vez, lo condiciona de tal manera que le ha impedido formar familia. Sus permanentes discusiones iluminan esta contradicción generacional y humana respecto al pasado añorado y el presente real. Bien logrados resultan los diálogos intergeneracionales bordeando estas tensiones:

- [...] Lo que a ti te pasa, papá, es que sigues viviendo en el mismo gueto, nunca has salido de ese lugar.

- ¿De qué gueto me estás hablando?

- De un gueto sin muros ni soldados. Escapaste, llegaste a América, vives en un sitio seguro, pero en realidad nunca has salido de allí... (GERTOPÁN, 2000)

Aunque con otros matices, estas discusiones recuerdan a las mantenidas por el protagonista de Réquiem para un viernes a la noche (1964), del argentino Germán Rozenmacher (Buenos Aires, 1936-1971), con su padre - cantor religioso en una sinagoga judía - básicamente alrededor del matrimonio mixto que violaría el respeto a la memoria de los exterminados por el nazismo. Pero Iósele va más allá de su pareja cristiana no aceptada por el padre: decide cambiarse el nombre por otro que no tenga resonancias judaicas, para iniciar una nueva vida, sin relación con la historia de horror y obligaciones que su progenitor le transmite. El tema del "nombre" despliega la cuestión de la identidad, cuando su padre viudo acusa a su único hijo de renegar de él, mutilar su continuidad cambiándose hasta aquello que lo definía ante los otros, su nombre. Aquello que, según la tradición, hace que un ser humano comience a existir sólo al ser nombrado por otro. José no está de acuerdo: 
Papá, eso que dices no es verdad. Las personas no son un nombre, no son un montón de letras que se juntan para formar una palabra. Las personas son seres con sentimientos, con color, con razas. No es un nombre el que da la identidad. (GERTOPÁN, 2000)

La solapa del mismo libro recuerda que, para el Talmud, el hombre posee tres nombres: el que le dan su padre y su madre, el que le dan los hombres y el que se hace a sí mismo. Y este último es el más valioso.

Esta aparente apuesta por una condición existencial - a tono con la ideología sartreana de la segunda posguerra - recibe, en el epílogo, un golpe demoledor que lo transforma en metáfora abierta a interpretaciones: enfermo y a punto de morir, su padre le confiesa que, en realidad, el supuesto apellido familiar no es el verdadero. Para sobrevivir, debió tomar prestado el de un polaco cristiano de su vecindad, que luego transmitió por herencia (y ese es, precisamente, el que José decidió cambiar). Elevado a la segunda potencia, este "cambio de nombre" resignifica toda la historia relatada y la construcción que la memoria ha hecho alrededor de ella.

El fin de esa trilogía se titula El retorno de Eva (2003). Reaparecen aquí personajes de la primera novela, cincuenta años después - en Israel, en Paraguay - junto a protagonistas de las nuevas generaciones. En especial Eva, una mujer que insinúa fuerte carga autobiográfica de la autora y cuyo nombre remite a la pecadora bíblica que prueba la manzana del conocimiento y, voluntariamente expulsada del Paraíso del barrio judío de Asunción, su ex esposo y toda su familia, va a vivir a Israel para iniciar una nueva vida que se revelará dura y distinta a las expectativas y mandatos paternos. Esta tercera generación judía-paraguaya que representa define su posición frente al judaísmo heredado y recordado: 
La angustia, el dolor, el arrepentimiento ante cualquier ruptura, desataba los sentimientos más trágicos impuestos por nuestra cultura, una cultura ancestral, la cultura de la pena, del desarraigo, de la culpa, del hambre, del abandono, de la pérdida, de la sobrevivencia como judíos errantes, heredada de nuestros patriarcas por ser el pueblo elegido por Dios, con el sufrimiento reflejado en el espíritu de una tradición. (GERTOPÁN, 2003)

De la generación de inmigrantes, "muy pocos quedaban ya con vida", mientras que los que siguieron continuaban

hablando en ídish y manteniendo ciertas costumbres que ya nosotros, su descendencia, no supimos comprender ni sostener. Era la evolución [...] Aquellos muertos cobraban cuerpo y participaban en mi vida como seres existentes y que, más adelante, escoltarían mi soledad. (GERTOPÁN, 2003)

\section{Pero lo cierto es que estos padres}

mantenían costumbres que no coincidían con este territorio. La historia de ellos se había desarrollado muy lejos, en otro contexto geográfico. Pertenecían a otras tierras, a otro clima, a otros sabores, a otros olores, a otros sufrimientos, a otras tradiciones. [...] En ese barrio (Palestina) me crié, sintiéndome salvaguardada por mis abuelos, por mis padres, por mis vecinos y mis hermanos mayores. [...] Me sentía amada, sostenida. Tenía el marco perfecto donde manejarme segura. Una prestada e inestable seguridad. $Y$ así fue que me crié detrás de una cortina de irrealidad. (GERTOPÁN, 2003) 
Pero la memoria de esas costumbres y esa forma de vida ya no le pertenecen a Eva: sólo su reminiscencia, la recreación de algo nunca experimentado, sólo escuchado de los mayores. Por ello es que decide cortar el hilo de la repetición y emprender una nueva vida en Israel: será madre soltera, se integrará con mucho esfuerzo y nunca totalmente al nuevo entorno, participará en reuniones de inmigrantes paraguayos en el país hebreo, en una de las cuales encontrará el nexo con su pasado.

Un rápido viaje a Asunción, por razones coyunturales, la reencuentra con su familia y con ese pasado a veces añorado, pero la convence, también, de que el regreso es imposible. El tema del matrimonio mixto de su hermano reabre las heridas de viejas discusiones familiares ("existían demasiadas diferencias en sus versiones sobre el significado de la identidad, como para que a uno le fuera comprensible el conflicto del otro"). La lucidez sobre su pasado mechado por los deseos paternos ("en nosotros quedaba marcado como un rastro de pena y culpabilidad cuando no éramos capaces de cumplir dichos mandatos") se traslada, otra vez, al tema de cómo ser nombrado: uno de sus amigos de infancia, Isaquito, ha recibido ese nombre

en memoria de un antepasado incinerado en los hornos de Treblinka, a quien continuamente recordaban, asociando el parecido físico de uno y otro. Desde su nacimiento lo condicionaron, a través de ese nombre heredado de otra persona, a sufrir dolores ajenos y a hacerse cargo de una historia de vida penosa y distante de la suya. (GERTOPÁN, 2003)

Como en las novelas anteriores de esta trilogía, el final elude el facilismo del happy end: el paso del tiempo ha sido cruel, muchos han muerto o sobreviven enfermos y ausentes sin haber podido cumplir sus anhelos de felicidad, su nuevo lugar de vida es Israel, pese a todos los contratiempos.

La nueva novela de Susana Gertopán que continúa esa trayectoria se titula El callejón oscuro (2010) y obtuvo en Asunción el Premio de Novela Inédita del Ateneo Lidia Guanes en el mismo año de su publicación. A semejanza de 
tantos autores que regresan por caminos diferentes a sus preguntas esenciales, la autora retoma paisajes y vivencias de la vida de inmigrantes judíos en Paraguay durante la segunda mitad del siglo XX, ahora desde una perspectiva novedosa: la existencia de "guetos espirituales" en esa tierra paraguaya bilingüe (guaraní y español) de indios, blancos, mestizos e inmigrantes, que encajan unos dentro de otros como en un juego de cajas chinas que nunca llega a (des) armarse en su totalidad.

Una carta del maduro Ariel - exiliado del país - a su primo José, que permaneció en el mismo escenario de infancia que ambos compartieron, le solicita ayuda para reconstruir fragmentos de su memoria lejana que se le escapan, en especial lo relacionado con una traumática experiencia en el "Callejón Oscuro" de su barrio cuando era niños. José le contestará a través de extensas notas y alguna carta final, que jalonan el recorrido de sus propias reminiscencias por esas veredas que ya no existen como tales, pero permanecen vívidamente en su imaginación.

Amante de la lectura, hijo de inmigrantes judíos escapados de Polonia poco antes que el horror nazi masacrara a sus familias, el "nuevo americano" crece rodeado de frases en ídish y miedos heredados de sus progenitores, que no le permiten el contacto con un mundo externo que siempre, a sus ojos, se presenta como amenazante.

José transmite esa extrañeza familiar de aves de paso que tienen la cabeza en Europa y el cuerpo ausente, en una tierra donde apenas hablan castellano y no entienden el guaraní:

[...] sentíamos que se trataba de un territorio prestado, temporal. De no sentir así, jamás saldríamos de ahí. La esperanza del retorno a nuestra patria no se cumpliría. Patria que en realidad nunca supe cuál era. Lo único seguro es que había que seguir rechazando, negando a este lugar como propio. Continuábamos siendo parte de un pueblo en el exilio. (GERTOPÁN, 2010) 
Ingresado a la adolescencia, José quiere "escapar" de esa situación confusa y de una herencia que lo ahoga y en verdad desconoce, ya que no lleva consigo incorporados los fantasmas de su abuela y sus padres. Primero cruzará la calle "segura" de su casa y se internará en el Mercado local, abigarrado y lleno de extraños personajes y coloridos inusuales: es laberinto, confusión, vida, barullo, animales, ropa, comida, plantas, lenguas desconocidas:

\section{En ese momento de mi existencia solamente los libros tenían guardado algo interesante que contarme. La lectura era mi único entretenimiento hasta el día en que crucé el puente imaginario y descubrí el otro mundo, el mundo del Mercado. (GERTOPÁN, 2010)}

Y más allá aún, poco después, descubrirá algo más lejos ese Callejón Oscuro y misterioso de gente y cosas, sumidos en un "estado salvaje" que simboliza el peligro y la fascinación al mismo tiempo.

José querrá salir, entonces, de ese gueto "seguro" que simboliza la tienda de su familia, donde los recuerdos enferman y "vivir duele". Cruzará la ancha avenida que divide dos mundos. Y en esa travesía construirá una nueva personalidad - con antecesores judíos, pero americana como la generación nativa a la que pertenece - sin dejar de intuir que, en definitiva, también los otros grupos humanos de esa realidad exterior se subdividen, una y otra vez, en "guetos particulares": el de los indios, el de los inmigrantes llenos de nostalgia por sus patrias perdidas, el de los mendigos y desclasados, el de los pobres y el de los ricos, el de aquellos que están casi fuera de la ley... todos con sus leyes particulares y modismos vitales.

La novela avanza con firmeza en la descripción de variados personajes y lugares, en un rico camino narrativo que se dirige hacia su desembocadura: la incógnita sobre ese episodio turbulento del Callejón Oscuro, que se resiste a ser evocado y que, finalmente, constituirá en sí mismo otra terrible metáfora sobre la vida y la muerte en este rincón alejado del mundo.

Susana Gertopán completa, de esta manera, un recorrido matizado y complejo sobre la temática de la identidad americana, desde nativos e inmigrantes 
cruzados por diversos exilios y trágicos momentos históricos que, en esta última producción, dirigen la luz de sus avatares hacia un entorno reconocible: la dictadura del general Stroessner y su Partido Colorado durante las décadas en las que transcurre la acción, quienes convierten por reflejo narrativo a todo el Paraguay en un gueto gigantesco, aislado del mundo y donde hasta hablar resulta peligroso. Metáfora final para esta valiosa novela de nuestro tiempo.

\section{Referencias}

GERTOPÁN, Susana. Barrio Palestina. Asunción:Arandura, 1998. . El nombre prestado. Asunción: Arandura, 2000. . El retorno de Eva. Asunción: Servilibro, 2003. . El callejón oscuro. Asunción: Servilibro, 2010.

ROZENMACHER, Germán. Requiem para un viernes a la noche. Buenos Aires: Talía, 1964. 